\title{
Changes in weight and body composition after initiating insulin therapy and their relationship with the metabolic control during the first year of type 1 diabetes in adults. InLipoDiab7 Study
}

\section{Maja Miętkiewska}

Department of Internal Medicine and Diabetology, Poznan University of Medical Sciences, Poland

(iD) https://orcid.org/0000-0002-4724-0744

Corresponding author: maja.mietkiewska@gmail.com

Aleksandra Uruska

Department of Internal Medicine and Diabetology, Poznan University of Medical Sciences, Poland

(iD) https://orcid.org/0000-0002-4631-1176

DOI: https://doi.org/10.20883/medical.e531
Keywords: diabetes mellitus type 1, weight change, body composition, insulin therapy, $\mathrm{HbA} 1 \mathrm{c}$, lipid profile

Published: 2021-12-29

How to Cite: Miętkiewska M, Uruska A. Changes in weight and body composition after initiating insulin therapy and their relationship with metabolic control during the first year of type 1 diabetes in adults. InLipo. Journal of Medical Science. 2021 Dec 29;90(4):e408. doi:10.20883/medical.e531.

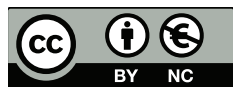

(c) 2021 by the author(s). This is an open access article distributed under the terms and conditions of the Creative Commons Attribution (CC BY-NC) licencse. Published by Poznan University of Medical Sciences

\section{ABSTRACT}

Introduction. As in the general population, an increase in the incidence of overweight has been observed in individuals with type 1 diabetes (T1DM). Nevertheless, weight gain in this group may contribute to the deterioration of the metabolic management. The aim of this study was to evaluate changes in the body weight and body composition after initiating insulin therapy and to assess their relationship with the metabolic management during the first year of T1DM in adults.

Material and Methods. The prospective analysis included 139 adults patients with newly diagnosed T1DM, treated with Intensive functional insulin therapy (IFI) from the onset of the disease (age $26.3 \pm 5.9$ years). Patients were assessed at the time of the diagnosis and after 12 months. Metabolic parameters, including the HbA1c and lipid profile were investigated. The group was divided according to weight gain during the follow-up period.

Results. Weight gain was observed in $68.3 \%$ of participants $(n=95)$. In most cases an increase in body fat was found $(41 \%$ vs $59 \% p=0.01)$. Changes in the body weight corresponded to significant changes in body composition. Conversely, HbA1c decreased during the follow-up in all groups. The highest reduction was observed in a group with "excessive weight gain". Additionally, a significant increase in high density lipoproteins was observed in each group. However, weight gain was not accompanied by a deterioration of the lipid profile.

Conclusions. Weight gain is a considerable problem among adults with newly diagnosed T1DM and is connected mainly with an increase of adipose tissue above the normal range. Changes in the body weight, associated with body composition changes, did not result in the dysfunctions of the metabolic management. 


\section{Introduction}

Type 1 diabetes mellitus (T1DM) is a chronic autoimmune disease characterized by absolute insulin deficiency. Furthermore, an increase in the incidence of overweight has been observed in individuals with T1DM [1]. In turn, excessive body weight (BW) and weight gain increase cardiovascular events and may contribute to the deterioration of the metabolic management, including lipid profile $[2,3]$.

Intensive functional insulin therapy (IFI) constitutes the treatment of choice in T1DM [4], where one of the side effects is an increase of BW [5]. In fact, beneficial changes in lipid parameters have been observed in the first months following the implementation of Intensive functional insulin therapy (IFI) [6]. However, it has been noted that a significant increase of BW as well as its time duration may suppress the beneficial effects of IFI [3].

Moreover, during the first year after implementing IFI, BW and body composition changed significantly, thus, monitoring of these changes might be necessary [8]. To date, there has been no prospective study analysing the changes in anthropometric parameters and body composition, as well as their relationship with the metabolic management in adults presenting with T1DM.

The aim of this study was to evaluate changes in the body weight and body composition after initiating $\mathrm{IFI}$ and their relationship with the metabolic parameters provided in the recommendations of Diabetes Poland [9], including the level of glycated haemoglobin (HbA1c) and lipid profile during the first year of T1DM in adults.

\section{Material and Methods}

The prospective analysis included 139 patients with newly diagnosed T1DM (42 women, mean age $26.3 \pm 5.9$ years), participants of the still ongoing Insulin Therapy and Lipoproteins Profile in Type 1 Diabetes Study (InLipoDiab1, NCT02306005). The study was approved by an appropriate bioethics committee, and the patients provided their written informed consent to participate in the study.

Exclusion criteria included age under 18 and above 35 years, presence of comorbidities and medication use for other disorders than T1DM, a lack of written consent, a lack of data at two control points.

The autoimmune aetiology was confirmed in all patients by the positive specific autoantibodies. The patients were treated with IFI using insulin pens from the onset of the disease. A description of the methodology has been outlined in the previous study [6].

Anthropometric data, including height, waist, and hip circumference, were measured by trained researchers using standardized meter measures. BW, fat mass (FM) [\%], free-fat mass (FFM) [kg], total body water (TBW) [I] content were measured by Body Composition Analyzer Tanita BC-418. The body mass index (BMI) and waist-to-hip ratio (WHR) were calculated on the basis of the following formulas: $\mathrm{BMI}=$ weight $(\mathrm{kg}) / \mathrm{squared}$ height $\left(\mathrm{m}^{2}\right)$ and WHR = waist circumference $(\mathrm{cm}) /$ hip circumference $(\mathrm{cm})$, respectively. The content of the adipose tissue was evaluated according to the Tanita scale.

Data with regard to a self-reported weight loss and the body weight prior to the diagnosis were provided by the participants and collected during the interview at baseline.

The daily dose of insulin (DDI) was defined as the requirement for insulin per kilogram body weight per day. This amount of insulin was calculated as the sum of units of long- and short-acting insulin. The final DDI at the time of the diagnosis was established on the last day of hospitalization when glucose levels reached the treatment target, and the patient could be discharged home. The DDI following one year since the diagnosis was based on the data derived from patients' self-monitoring logs from the previous month.

The lipid profile, including the levels of $\mathrm{TC}, \mathrm{HDL}$, and triglycerides, was measured using a Cobas 6000 biochemistry analyser (Roche Diagnostics, Basel, Switzerland), by means of enzymatic colorimetric methods. Low-density lipoprotein levels were calculated by the Friedewald formula, whereas glycated haemoglobin (HbA1c) concentration was assessed by a turbidimetric inhibition immunoassay (Cobas 6000, Roche Diagnostics).

The study group was divided according to the extent of change in BW expressed in percentages during the first year of T1DM into 2 subgroups:

$\%$ BW change $=\frac{\Delta \text { EW after } 1 \text { year }[\mathrm{kg}]}{\text { baseline } \mathrm{BW}[\mathrm{kg}]} * 100 \%$ 
The change expressed only as kilograms may be misleading and does not comprise the differentiation in initial BW, as well as the sex-related differences [7]. Therefore, the following thresholds were adopted:

1 Group 1 - weight loss (change in initial BW $<0 \%) ; n=41(29.5 \%)$.

, Group $2-$ minimal weight gain (change in initial BW from 0 to $\leq 5 \%) ; n=43(30.9 \%)$.

, Group 3 - excessive weight gain (change in initial $\mathrm{BW}>5 \%) ; \mathrm{n}=55(39.6 \%)$.

Statistical analysis

The statistical analysis was performed using STATISTICA, version 13 (StatSoft, Inc, Tulsa, OK, USA). Only the participants with the set of data at two control points were included in the statistical analysis. All data were presented as median values and interquartile ranges (IQRs), and the number (percentage) of patients. First, the data at baseline and follow-up were compared, then, participants were divided into three groups. The normality of data distribution was tested using the Shapiro-Wilk test, and the comparative analysis of three independent groups was performed using the Kruskal-Wallis test. When statistically significant differences occurred, an appropriate posthoc test was applied (Bonferroni, T2 Tamhane's test). In comparison of these two time periods, the student's t-test for dependent samples, or its nonparametric equivalent, i.e., the Wilcoxon test, was used. Moreover, $\mathrm{p}$-value $<0.05$ was considered statistically significant.

\section{Results}

\section{Baseline}

\subsection{Characteristic of the study population}

The study involved 139 individuals, with 41 (29.5\%) included in the weight loss group (1), 43 (30.9\%) were classified to the minimal weight gain group (2), and 55 (39.6\%) - to the excessive weight gain group (3). The compared groups were equal in number, $p=0.29$. Characteristics are presented in Table 1.

Table 1. Characteristics of the research group. The anthropometric data and body composition at baseline and during the follow-up

\begin{tabular}{|c|c|c|c|c|c|}
\hline & & Weight loss (1) & Minimal weight gain (2) & Excessive weight gain (3) & $\mathrm{p}$-value \\
\hline \multirow[t]{2}{*}{ Sex, n (\%) } & Female & $10(24.4)$ & $16(37.2)$ & $16(29.1)$ & \multirow[t]{2}{*}{$p=0.43$} \\
\hline & Male & $31(75.6)$ & $27(62.8)$ & $39(70.9)$ & \\
\hline \multicolumn{2}{|l|}{ Increase in body fat, $\mathrm{n}(\%)$} & $8(20.5)$ & $27(67.5)$ & $47(85.5)$ & $\mathrm{p}<0.001$ \\
\hline \multirow[t]{2}{*}{ Body weight, kg } & Baseline & $76.6(66.5-82.5)$ & $68.3(57.8-77.8)$ & $67.9(56.8-78.5)$ & $p=0.06$ \\
\hline & Follow-up & $72.9(63.5-77.3)$ & $70.5(59.2-78.9)$ & $76.3(64.0-85.4)$ & $p=0.29$ \\
\hline \multicolumn{2}{|c|}{ Bodyweight before the diagnosis, kg } & $83.3(70.2-87.5)$ & $75.9(67.2-84.3)$ & $76.25(63.8-89.8)$ & $p=0.26$ \\
\hline \multicolumn{2}{|c|}{ Self-reported weight loss, kg } & $-5.0(-10.0-(-3.8))$ & $-6.0(-10.0-(-4))$ & $-7.5(-10.0-(-5.0))$ & $p=0.16$ \\
\hline \multirow[t]{2}{*}{$\mathrm{BMI}, \mathrm{kg} / \mathrm{m}^{2}$} & Baseline & $23.1(21.6-26.3)$ & $22.4(20.1-24.2)$ & $22.0(19.4-24.6)$ & $p=0.1$ \\
\hline & Follow-up & $22.1(20.4-25.3)$ & $22.7(20.6-24.9)$ & $23.8(21.5-26.7)$ & $p=0.04_{c}$ \\
\hline \multirow[t]{2}{*}{ WHR } & Baseline & $0.9(0.8-0.9)$ & $0.8(0.8-0.9)$ & $0.8(0.8-0.9)$ & $p=0.28$ \\
\hline & Follow-up & $0.8(0.8-0.9)$ & $0.8(0.8-0.8)$ & $0.8(0.8-0.9)$ & $p=0.69$ \\
\hline \multirow[t]{2}{*}{ Waist circumferences, $\mathrm{cm}$} & Baseline & $87.0(81.0-91.0)$ & $80.0(72.0-85.0)$ & $80.0(73.0-90.0)$ & $p=0.04 a$ \\
\hline & Follow-up & $80.0(74.0-84.0)$ & $80.5(75.0-85.0)$ & $81.0(74.0-93.0)$ & $p=0.53$ \\
\hline \multirow[t]{2}{*}{ Fat mass, $\%$} & Baseline & $18.0(12.0-23.5)$ & $19.1(12.4-22.5)$ & $14.4(7.5-21.3)$ & $p=0.07$ \\
\hline & Follow-up & $12.7(9.6-18.1)$ & $18.8(12.15-22.9)$ & $18.4(12.7-26.0)$ & $p=0.009_{c}$ \\
\hline \multirow[t]{2}{*}{ Free-fat mass, $\mathrm{kg}$} & Baseline & $62.8(54.9-67.3)$ & $59.15(44.0-66.2)$ & $59.7(45.4-66.0)$ & $p=0.25$ \\
\hline & Follow-up & $62.8(54.7-66.7)$ & $60.5(43.1-67.9)$ & $63.0(46.0-69.7)$ & $p=0.57$ \\
\hline \multirow[t]{2}{*}{ Total body water, I } & Baseline & $45.9(40.2-49.3)$ & $43.3(32.5-48.5)$ & $43.7(33.5-48.3)$ & $p=0.3$ \\
\hline & Follow-up & $44.1(40.0-48.8)$ & $44.3(31.6-49.7)$ & $46.5(33.7-51.0)$ & $p=0.55$ \\
\hline
\end{tabular}

Abbreviations: BMI, body mass index; WHR, wait-to-hip ratio.

Gender, education, body fat, smoking status, physical activity according to the weight changes status was performed using chi-square test. Comparative analysis of anthropometric data and body composition at baseline and the follow-up by weight change group was performed using the Kruskal-Wallis test. The results are presented as median and interquartile range.

${ }_{\mathrm{a}} \mathrm{P}<0.05$ Weight loss vs. Minimal weight gain

${ }_{b} \mathrm{P}<0.05$ Minimal weight gain vs. Excessive weight gain

${ }_{c} \mathrm{P}<0.05$ Weight loss vs. Excessive weight gain 


\subsection{Anthropometric and body composition at baseline}

Anthropometric and body composition data at onset are listed in Table 1. Statistically significant differences regarding anthropometric and body composition variables at onset were observed only for waist circumference between groups 1 and 2.

\subsection{Metabolic management at baseline}

Data regarding the metabolic control in each group are presented in Table 2. Significant differences at baseline were applicable only to HbA1c. Furthermore, neither lipid parameters nor DDI differed significantly between the groups at the onset.

\section{Data at the follow-up (after 12 months} from onset)

\subsection{Anthropometric data and body composition at the follow-up}

After one year from the diagnosis compared to baseline, a higher percentage of patients from group 3 presented an increased adipose tissue content above the normal range $(p=0.02)(9.1 \%$ vs. $25.5 \%$ ) (Figure 1). Additionally, following one year from the diagnosis, statistically significant differences related to the median BMI and body fat content were observed (Table 1).

\subsection{Metabolic management at the follow-up}

Statistically significant metabolic management differences were not observed after one year from the onset between the three groups (Table 2).

\section{Changes during 12 months of observation}

\subsection{Changes in anthropometric parameters and body composition}

The comparative analysis between the three groups is presented in Table 3.

WHR in group 1 decreased $(P=0.001)$, whereas in other groups no statistically significant differences were found. Moreover, waist circumference in group 1 decreased significantly $(P<0.001)$ and increased in group 3 . In group 1 , the median FFM was reduced $(P=0.02)$ and a significant increase of the median FFM in groups $2(P=0.008)$ and $3(P<0.001)$ was observed. In addition, in group 1 , TBW decreased with statistical significance $(P=0.01)$. In the course of the observation period, TBW significantly increased among groups 2 $(P=0.007)$ and $3(P<0.001)$. Moreover, FM correlated with weight change in groups 1 and 3 , whereas in group 1, the median content of the adi-

Table 2. Comparison of the metabolic management at baseline and the follow-up according to weight change groups

\begin{tabular}{|c|c|c|c|c|c|}
\hline & & Weight loss (1) & Minimal weight gain (2) & Excessive weight gain (3) & p-value \\
\hline \multirow[t]{2}{*}{$\mathrm{HbA1c}, \%$} & Baseline & $10.10(9.5-11.6)$ & $10.5(9.5-12.1)$ & $12.1(11.0-12.8)$ & $\mathrm{p}<0.001^{\mathrm{bc}}$ \\
\hline & Follow-up & $6.6(5.8-7.9)$ & $6.5(6.1-7.3)$ & $6.8(6.2-7.7)$ & $p=0.58$ \\
\hline \multirow[t]{2}{*}{$\mathrm{HbA1c}, \mathrm{mmol} / \mathrm{l}$} & Baseline & $87(80-103)$ & $91(80-109)$ & $109(97-116)$ & $\mathrm{p}<0.001^{\mathrm{bc}}$ \\
\hline & Follow-up & $49(39-63)$ & $48(43-56)$ & $51(44-61)$ & $p=0.59$ \\
\hline \multirow[t]{2}{*}{$\mathrm{TC}, \mathrm{mmol} / \mathrm{l}$} & Baseline & $4.5(3.6-5.3)$ & $4.3(3.9-4.7)$ & $4.3(3.7-5.0)$ & $p=0.89$ \\
\hline & Follow-up & $4.8(3.8-5.0)$ & $4.5(3.9-5.1)$ & $4.5(3.9-5.2)$ & $p=0.87$ \\
\hline \multirow[t]{2}{*}{$\mathrm{HDL}, \mathrm{mmol} / \mathrm{l}$} & Baseline & $1.2(0.8-1.4)$ & $1.2(0.9-1.5)$ & $1.2(1.0-1.3)$ & $p=0.85$ \\
\hline & Follow-up & $1.7(1.5-2.0)$ & $1.9(1.5-2.3)$ & $1.7(1.4-2.1)$ & $p=0.16$ \\
\hline \multirow[t]{2}{*}{ LDL, mmol/l } & Baseline & $2.5(1.7-3.4)$ & $2.5(2.1-2.9)$ & $2.5(2.0-3.1)$ & $p=0.81$ \\
\hline & Follow-up & $2.3(1.7-2.7)$ & $2.1(1.7-2.6)$ & $2.3(1.6-2.9)$ & $p=0.8$ \\
\hline \multirow[t]{2}{*}{$\mathrm{TG}, \mathrm{mmol} / \mathrm{l}$} & Baseline & $1.1(0.9-1.7)$ & $1.1(0.9-1.8)$ & $1.3(0.9-1.3)$ & $p=0.74$ \\
\hline & Follow-up & $0.9(0.6-1.6)$ & $0.7(0.5-1.1)$ & $1.0(0.7-1.2)$ & $p=0.26$ \\
\hline \multirow[t]{2}{*}{ DDI, IU/day } & Baseline & $0.1(0.1-0.2)$ & $0.1(0.1-0.3)$ & $0.2(0.1-0.4)$ & $p=0.35$ \\
\hline & Follow-up & $0.3(0.2-0.6)$ & $0.3(0.2-0.4)$ & $0.3(0.2-0.5)$ & $p=0.76$ \\
\hline
\end{tabular}

Abbreviations: DDI, daily dose of insulin; HbA1c, glycated haemoglobin; HDL, high density lipoprotein; LDL, low density lipoprotein; TC, total cholesterol; TG, triglyceride.

The results are presented as median and interquartile range. Comparative analysis was performed using the Kruskal-Wallis test.

${ }_{a} P<0.05$ Weight loss vs. Minimal weight gain

${ }_{b} \mathrm{P}<0.05$ Minimal weight gain vs. Excessive weight gain

${ }_{c} \mathrm{P}<0.05$ Weight loss vs. Excessive weight gain 
pose tissue significantly decreased $(P<0.001)$. However, the opposite effect was observed in group $3(P<0.001)$.

\subsection{Changes in the metabolic management}

In each group, the median level of $\mathrm{HbA} \mathrm{Cc}$ decreased significantly $(p<0.001)$, although the reduction of HbAlc was greater in group 3 than in group 1 $(p=0.002)$ (Table 3). The annual distributions of HbA1c in each group are shown in Figure 2.

In each group, the median TG level decreased significantly (for group $1 p=0.01$; for group 2 and $3 p<0.001$ ). Additionally, although no statistically significant differences were observed between the two time periods in either group regarding TC, a significant reduction in LDL in groups 2

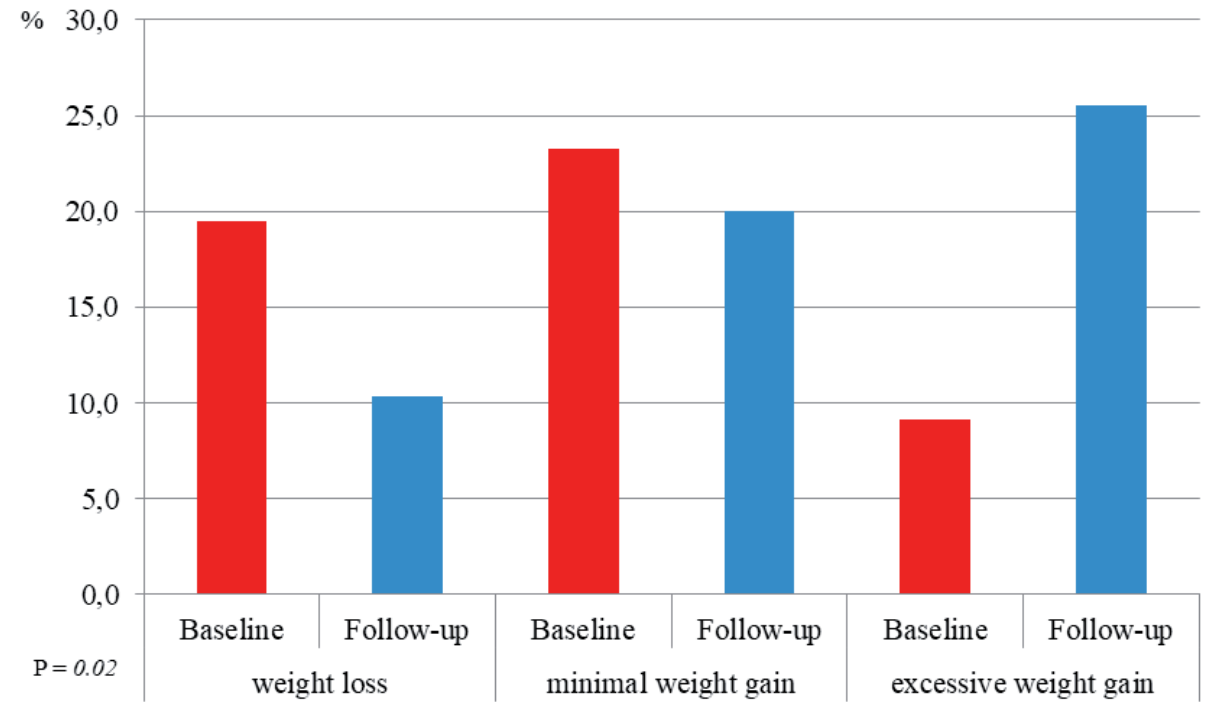

Figure 1. Percentages of subjects with the adipose tissue above normal in relation to weight gain group baseline and at follow up

Table 3. Changes in the anthropometric data, body composition, and the metabolic management by weight change group during the follow-up

\begin{tabular}{|c|c|c|c|c|}
\hline & Weight loss (1) & Minimal weight gain (2) & Excessive weight gain (3) & P-value \\
\hline$\Delta$ Body weight, $\mathrm{kg}$ & $-3.2(-5.3-(-1.2))$ & $1.9(0.9-2.4)$ & $6.6(4.7-9.6)$ & $\mathrm{p}<0.001^{\mathrm{abc}}$ \\
\hline \%change in body weight, \% & $-4.5(-6.9-(-1.8))$ & $2.8(1.3-4.0)$ & $9.4(6.6-14.1)$ & $\mathrm{p}<0.001^{\mathrm{abc}}$ \\
\hline$\Delta B M I, \mathrm{~kg} / \mathrm{m}^{2}$ & $-1.1(-1.7-(-0.4))$ & $0.7(0.3-0.8)$ & $2.09(1.5-3.01)$ & $\mathrm{p}<0.001^{\mathrm{abc}}$ \\
\hline$\Delta$ WHR & $-0.07(-0.8-(-0.0))$ & $-0.02(-0.69-0.0)$ & $-0.02(-0.8-0.01)$ & $p=0.39$ \\
\hline$\Delta$ Waist circumferences, cm & $-9.0(-79.0-(-2.0))$ & $0.0(-64-5.0)$ & $-1.0(-74.0-5.0)$ & $p=0.05$ \\
\hline$\Delta$ Fat mass, $\%$ & $-2.5(-5.1-(-0.4))$ & $0.75(-0.6-2.7)$ & $4.4(1.5-6.7)$ & $\mathrm{p}<0.001^{\mathrm{abc}}$ \\
\hline$\Delta$ Free-fat mass, $\mathrm{kg}$ & $-0.5(-1.4-0.2)$ & $0.6(-0.5-1.6)$ & $2.5(0.6-4.5)$ & $\mathrm{p}<0.001^{\mathrm{abc}}$ \\
\hline$\Delta$ Total body water, I & $-0.5(-1.2-0.0)$ & $0.4(-0.3-1.2)$ & $1.8(0.2-3.9)$ & $\mathrm{p}<0.001^{\mathrm{ac}}$ \\
\hline$\Delta \mathrm{HbA1c}, \%$ & $-3.7(-4.7-(-1.5))$ & $-4.1(-6.0-(-2.4))$ & $-5.0(7.1-(-2.7))$ & $p=0.002^{c}$ \\
\hline$\Delta \mathrm{HbAlc}, \mathrm{mmol} / \mathrm{l}$ & $-36(-47-(-16))$ & $-47(-66-(-25))$ & $-55(-74-(-36))$ & $p=0.002^{c}$ \\
\hline$\Delta \mathrm{TC}, \mathrm{mmol} / \mathrm{l}$ & $0.36(-0.2-0.9)$ & $0.03(-0.6-0.8)$ & $-0.01(-0.4-0.4)$ & $p=0.18$ \\
\hline $\mathbf{\Delta H D L}, \mathrm{mmol} / \mathrm{l}$ & $0.6(0.4-0.8)$ & $0.1(0.4-1.0)$ & $0.5(0.2-0.9)$ & $p=0.35$ \\
\hline$\Delta \mathrm{LDL}, \mathrm{mmol} / \mathrm{l}$ & $-0.1(-0.7-0.2)$ & $-0.5(-1.0-0.2)$ & $-0.3(-0.6-0.3)$ & $p=0.75$ \\
\hline$\Delta \mathrm{TG}, \mathrm{mmol} / \mathrm{l}$ & $-0.3(-0.6-0.1)$ & $-0.5(-1.0-(-0.2))$ & $-0.3(-0.6-(-0.1))$ & $p=0.48$ \\
\hline
\end{tabular}

Abbreviations: BMI, body mass index; WHR, wait-to-hip ratio; HbA1c, glycated haemoglobin; TC, total cholesterol ;HDL, high density lipoprotein; LDL, low density lipoprotein ; TG, triglyceride.

The results are presented as median and interquartile range.

Comparative analysis was performed using the Kruskal-Wallis test.

$\boldsymbol{\Delta}$; for example, $\mathbf{\Delta}$ body weight was defined as the difference between the body weight at the follow-up [kg] and onset [kg]

${ }_{a} \mathrm{P}<0.05$ Weight loss vs. Minimal weight gain

${ }_{b} \mathrm{P}<0.05$ Minimal weight gain vs. Excessive weight gain

${ }_{c} \mathrm{P}<0.05$ Weight loss vs. Excessive weight gain 
$(p=0.005)$ and $3(p=0.002)$ was demonstrated. Furthermore, in each group, a significant increase in HDL was observed $(p<0.001)$; the lowest increase was shown in group 3 , while the highest was found in group 2. The annual distributions of HDL in each group are shown in Figure 3. However, no differences were observed between groups with regard to the changes in lipid profile according to weight gain (Table 2 and $\mathbf{3}$ ).

\section{Discussion}

The study results clearly indicated that BW changes following T1DM diagnosis. Weight gain, observed in $68.3 \%$ of participants, was mainly related to an FM increase and increased adipose tissue above the normal range. Moreover, changes in BW correspond to significant changes in body composition (TBW, FM, FFM). Nevertheless,

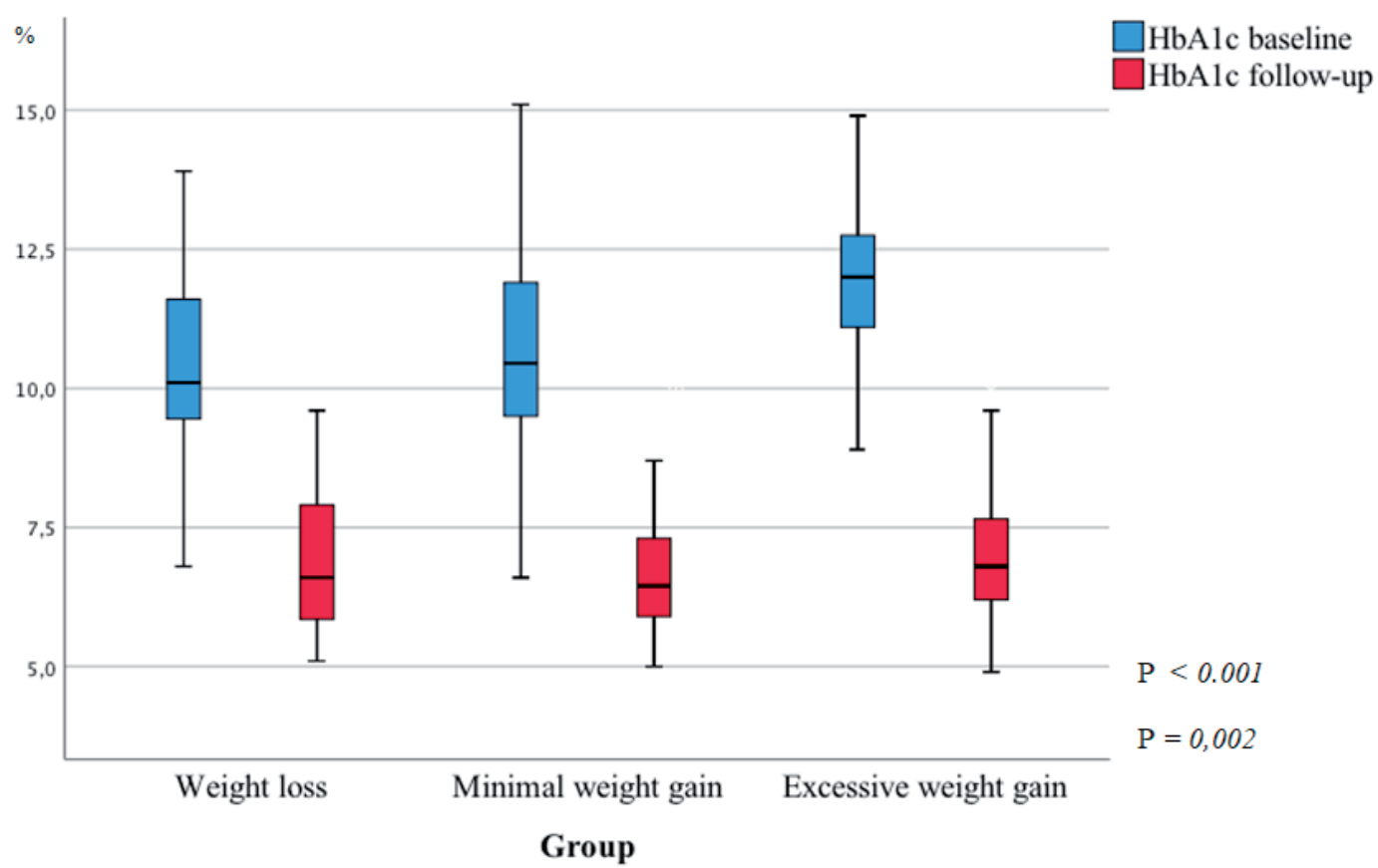

Figure 2. The annual distributions of $\mathrm{HbA1c}$ in each group

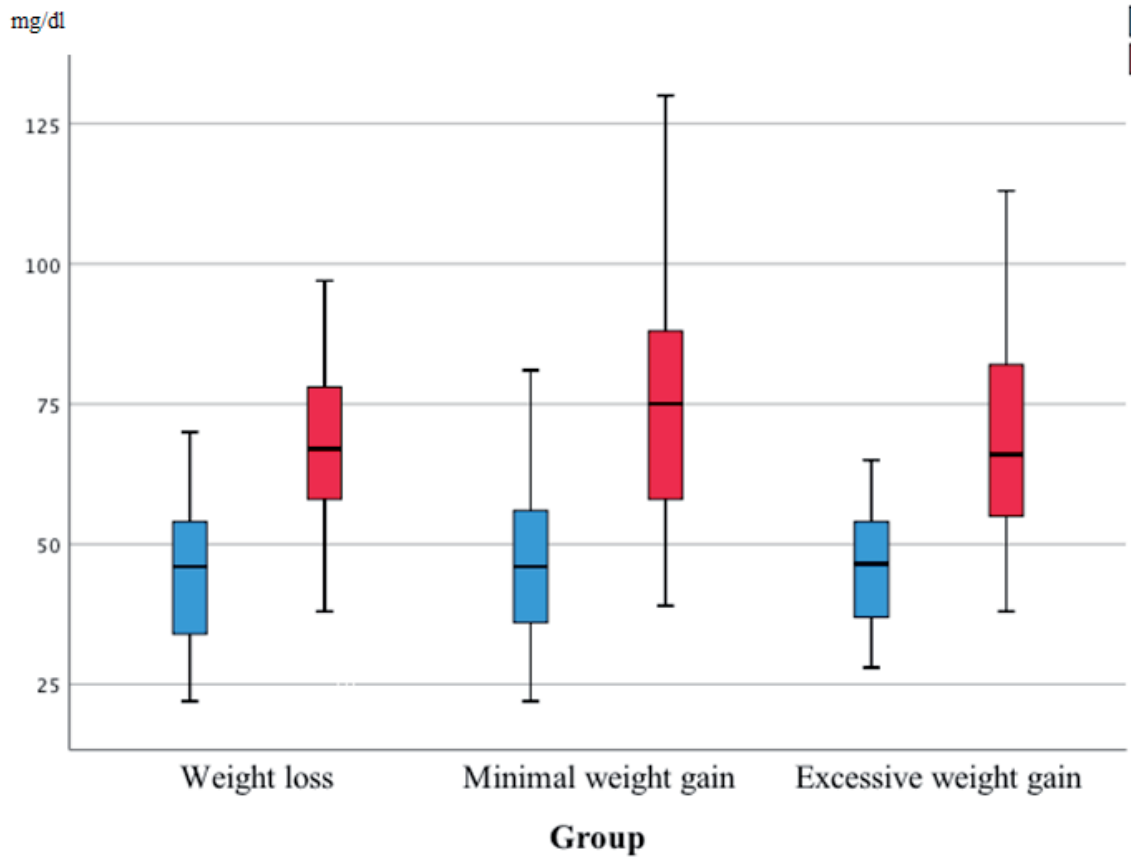

HDL baseline

HDL follow-up

Figure 3. The annual distributions of HDL in each group 
the available literature with regard to BW, body composition and their association with the metabolic management in adults with newly diagnosed T1DM is scarce.

Weight gain among the participants of the Diabetes Control and Complications Trial (DCCT) was increased most rapidly within the first year of observation (an average of $3.3 \mathrm{~kg}$ ). It was mainly related to an increase of FFM [10], and progressed with time [2]. However, in DCCT, the follow-up period did not commence at the onset of the disease.

According to the study by Carlson and Campbell [12], an FM increase accounted for 2.4 of the $2.6 \mathrm{~kg}$ of increased weight.

The lack of FFM changes can be accounted for by the small study population $(n=6)$ and the short duration of the follow-up (2 months). In turn, other observational studies, also with the participation of a small study population $(n=10)$, demonstrated that during the first year after the onset of T1DM the mean increase in BW is 6.5\% $(4.3 \pm 2.9 \mathrm{~kg})$, with a simultaneous increase in $\mathrm{FM}$ and FFM [8].

The participants in our study whose BW decreased during observation, also experienced a significant decrease in FM, FFM, and TBW, whereas TBW as part of FM was found to increase with an increase in fat content [13].

The adipose tissue, including the visceral adipose tissue, is an independent predictor of insulin sensitivity and a critical factor modulating lipid and glucose homeostasis. In individuals with T1DM, the influence on insulin sensitivity is revealed by $\mathrm{BMI}, \mathrm{TG}$, waist circumference, visceral adipose tissue, and total FM [14]. Therefore, it is crucial to monitor BW and body composition among adults with newly diagnosed T1DM in terms of the development of insulin resistance and progression. It seems particularly essential, since a decreased insulin sensitivity is a well-known risk factor for complications in this group [15].

Insulin deficiency, as a catabolic state, is correlated with a loss of nitrogen and FFM. As the previous study revealed, the pre-diagnosis unintentional weight loss as high as $6.3 \pm 2.5 \mathrm{~kg}$ may affect body composition differently depending on the course of the disease and the changes which occur prior to the diagnosis. In fact, weight loss before the diagnosis may affect FM and FFM [8]. Therefore, the baseline body composition appears to be essential and may largely determine the subsequent metabolic management.

Although the initial BW and BMI did not differ significantly between the groups, it is noteworthy that among individuals whose weight significantly decreased, both BW and BMI were higher at the time of the diagnosis than in patients whose BW increased. This observation is consistent with the findings of Kim et al., wherein persons who lost weight presented a BMI $>25 \mathrm{~kg} / \mathrm{m}^{2}$ more frequently [16]. However, the most alarming observation was the fact that weight gain in such a short period of time - within only one year of observation - was primarily associated with an increase in the adipose tissue above the norm.

The second aim of the study was to analyse whether changes in BW affect the metabolic management. It turned out that the metabolic management changed significantly during the first year of the disease, although there were no significant differences between groups in terms of the level of weight gain. Nonetheless, it was observed that patients in group 1 experienced a slightly smaller reduction in LDL compared to groups 2 and 3. Each group demonstrated an increase in HDL; however, the lowest increase was in group 3. Moreover, TC increased slightly in each group, although this change was not statistically significant.

Our results are consistent with the literature. In fact, Dayem et al. [4] showed a relationship of excess BW with deteriorated lipid parameters, including significantly lower HDL, higher LDL, TC, and TG. However, these findings refer to the pediatric population and, hence, cannot be directly translated into other age groups. EURODIAB Prospective Complications Study results [11] indicate that changes in lipid profile are less favourable in the group of patients who significantly increased their BW ( $\geq 5 \mathrm{~kg}$ ). A weight change one year after the T1DM diagnosis did not significantly affect the lipid profile, and the changes were only minor. Additionally, an increase of HDL occurred independently of the weight change; however, the smallest increase was observed in the group with the excessive weight gain.

It is worth bearing in mind that even though a weight gain was observed, the median BMI was within the reference range. This, in turn, emphasizes the disadvantages of BMI measurement alone, and further suggests the necessity of 
monitoring the other anthropometric and body composition parameters in order to observe the clinically significant changes.

Analysing glycaemic control, $\mathrm{HbA} 1 \mathrm{c}$ decrease was observed in the entire group. Individuals who presented a significant weight gain also demonstrated the highest reduction of $\mathrm{HbaA1c}$, although simultaneously they had the highest HbA1c at the time of the diagnosis. In this respect our results are consistent with those demonstrated by Yamada et al. [17], who has suggested that neither BMI nor BW determines HbA1c among the non-obese T1DM subjects, and good control is associated with an appropriate insulin dose showing a strong correlation with BW. However, in our study, DDI did not differ significantly between groups at the onset. Therefore, weight gain observed in our study was a consequence of a lifestyle, rather than the insulin dose. The relationship between weight gain and HbAlc concentration seems to be an interesting area to explore. More favourable changes in HbAlc in group 3 can be accounted for by increased FFM. Muscle mass, a component of FFM, is involved in insulin-dependent glucose uptake, making it a vital element in maintaining carbohydrate control [18]. It has been suggested that hypoglycaemia, more frequently observed in patients who gained weight, may contribute to better $\mathrm{HbA1c}$ results $[10,11]$.

A limitation of this study is the lack of information regarding diet. However, all participants underwent the same educational course with a dietitian. Moreover, the data including physical activity and BW before the diagnosis were provided by participants. Finally, we did not investigate the rate of hypoglycaemia, and we were not able to determine body composition prior to the diagnosis.

Concluding, weight gain seems to be a considerable issue among adults with newly diagnosed T1DM, particularly since it increases the adipose tissue above the normal range. However, an increase in the body weight, associated with unfavourable changes in the body composition, did not adversely affect the metabolic management, including $\mathrm{HbA} 1 \mathrm{c}$ and lipid profile.

\section{Perspectives}

The abovementioned changes in the body weight require careful consideration in the course of
T1DM since the very beginning of the disease. Another crucial factor seems to be the initial BW at the onset and weight loss before the diagnosis. Our results clearly indicated that in adults with T1DM, weight gain was present from the onset of the disease. The recognition of this fact allows for the timely implementation of the preventive measures or the fastest possible effective therapy aiming to prevent the excessive weight gain. Moreover, the consequences of obesity are widely known [19], and are also applicable to the population of patients suffering from T1DM. The surveillance rate, despite a great progress, is still lower in T1DM as compared with the healthy individuals [20]. Thus, it is crucial to identify the factors which can improve the prognosis in T1DM. This study highlights one of such factors, and constitutes a background for future analysis and interventional studies.

\section{Acknowledgements}

Acknowledgment and sincere thanks to Agnieszka Seraszek-Jaros, who helped in the statistical analysis.

\section{Contributions}

AU conceived the idea for the study. All authors contributed to the design of the research and were involved in data collection. MM analysed the data. All authors approved the final version of the manuscript.

\section{Conflict of interest statement}

The authors declare no conflict of interest.

\section{Funding sources}

There are no sources of funding to declare.

\section{References}

1. Miyazawa I, Kadota A, Miura K, Okamoto M, Nakamura T, Ikai T, Maegawa H, Ohnishi A. Twelve-year trends of increasing overweight and obesity in patients with diabetes: the Shiga Diabetes Clinical Survey. Endocr J. 2018 May 28;65(5):527-536. doi: 10.1507/endocrj. EJ17-0415. Epub 2018 Mar 10. Erratum in: Endocr J. 2021;68(2):251. PMID: 29526989.

2. Purnell JQ, Hokanson JE, Marcovina SM, Steffes MW, Cleary PA, Brunzell JD. Effect of excessive weight gain with intensive therapy of type 1 diabetes on lipid levels and blood pressure: results from the DCCT. Diabetes Control and Complications Trial. JAMA. 1998 Jul 8;280(2):140-6. doi: 10.1001/jama.280.2.140. Erratum in: JAMA 1998 Nov 4;280(17):1484. PMID: 9669786; PMCID: PMC2622729.

3. Purnell JQ, Braffett BH, Zinman B, Gubitosi-Klug RA, Sivitz W, Bantle JP, Ziegler G, Cleary PA, Brunzell JD; DCCT/EDIC Research Group. Impact of Excessive Weight Gain on Cardiovascular Outcomes in Type 
1 Diabetes: Results From the Diabetes Control and Complications Trial/Epidemiology of Diabetes Interventions and Complications (DCCT/EDIC) Study. Diabetes Care. 2017 Dec;40(12):1756-1762. doi: 10.2337/ dc16-2523. PMID: 29138273; PMCID: PMC5711332.

4. Diabetes Control and Complications Trial Research Group, Nathan DM, Genuth S, Lachin J, Cleary P, Crofford O, Davis M, Rand L, Siebert C. The effect of intensive treatment of diabetes on the development and progression of long-term complications in insulin-dependent diabetes mellitus. N Engl J Med. 1993 Sep 30;329(14):977-86. doi: 10.1056/ NEJM199309303291401. PMID: 8366922.

5. Adverse events and their association with treatment regimens in the diabetes control and complications trial. Diabetes Care. 1995 Nov;18(11):1415-27. doi: 10.2337/diacare.18.11.1415. PMID: 8722064.

6. Cieluch A, Uruska A, Grzelka-Woźniak A, Niedźwiecki P, Flotyńska J, Zozulińska-Ziółkiewicz D. Changes in high-density lipoprotein cholesterol (HDL-C) level and the ratio of triglycerides to HDL-C during the first year of type 1 diabetes. Pol Arch Intern Med. 2019 Sep 30;129(9):598-604. doi: 10.20452/pamw.14920. Epub 2019 Aug 5. PMID: 31379357.

7. Horne JR, Gilliland JA, O'Connor CP, Seabrook JA, Madill J. Change in Weight, BMI, and Body Composition in a Population-Based Intervention Versus Genetic-Based Intervention: The NOW Trial. Obesity (Silver Spring). 2020 Aug;28(8):1419-1427. doi: 10.1002/oby.22880. PMID: 32935529.

8. Rosenfalck AM, Almdal T, Hilsted J, Madsbad S. Body composition in adults with Type 1 diabetes at onset and during the first year of insulin therapy. Diabet Med. 2002 May;19(5):417-23. doi: 10.1046/j.14645491.2002.00702.x. PMID: 12027931.

9. Aleksandra A, Bandurska-Stankiewicz E, Borys S, Budzyński A, Cyganek K, Cypryk K, Czech A, Czupryniak L, Drzewoski J, Dzida G, Dziedzic T, Franek E, Gajewska D, Gawrecki A, Górska M, Grzeszczak W, Gumprecht J, Idzior-Waluś B, Jarosz-Chobot P, Kalarus $Z$, Karczewska-Kupczewska M, Klupa T, Koblik T, Kokoszka A, Korzon-Burakowska A, Kowalska I, Krętowski A, Majkowska L, Małecki M, Mamcarz A, Mirkiewicz-Sieradzka B, Młynarski W, Moczulski D, Myśliwiec $M$, Narkiewicz $K$, Noczyńska A, Rymaszewska J, Sieradzki J, Skupień J, Solnica B, Strączkowski M, Strojek K, Szadkowska A, Szelachowska M, Szypowska A, Uruska A, WenderOżegowska E, Wierusz-Wysocka B, Witek $P$, Wolnik $B$, Wyleżoł $M$, Wylęgała $E$, Zozulińska-Ziółkiewicz D. 2021 Guidelines on the management of patients with diabetes. A position of Diabetes Poland. Clin Diabetol 2021 Feb;10 (1), s. 1-113. doi: 10.5603/DK.2021.0001.

10. The Diabetes Control And Complications Trial Research Group. Influence of intensive diabetes treatment on body weight and composition of adults with type 1 diabetes in the Diabetes Control and Complications Trial. Diabetes Care. 2001 Oct;24(10):171121. doi: 10.2337/diacare.24.10.1711. PMID: 11574431; PMCID: PMC2663516.
11. Ferriss JB, Webb D, Chaturvedi N, Fuller JH, Idzior-Walus B; EURODIAB Prospective Complications Group. Weight gain is associated with improved glycaemic control but with adverse changes in plasma lipids and blood pressure isn Type 1 diabetes. Diabet Med. 2006 May;23(5):557-64. doi: 10.1111/j.14645491.2006.01847.x. PMID: 16681565.

12. Carlson MG, Campbell PJ. Intensive insulin therapy and weight gain in IDDM. Diabetes. 1993 Dec;42(12):1700-7. doi: 10.2337/diab.42.12.1700. PMID: 8243815.

13. Duren DL, Sherwood RJ, Czerwinski SA, Lee M, Choh AC, Siervogel RM, Cameron Chumlea W. Body composition methods: comparisons and interpretation. J Diabetes Sci Technol. 2008 Nov;2(6):1139-46. doi: 10.1177/193229680800200623. PMID: 19885303; PMCID: PMC2769821.

14. Schauer IE, Snell-Bergeon JK, Bergman BC, Maahs $\mathrm{DM}$, Kretowski A, Eckel RH, Rewers $\mathrm{M}$. Insulin resistance, defective insulin-mediated fatty acid suppression, and coronary artery calcification in subjects with and without type 1 diabetes: The CACTI study. Diabetes. 2011 Jan;60(1):306-14. doi: 10.2337/db100328. Epub 2010 Oct 26. PMID: 20978091; PMCID: PMC3012187.

15. Kilpatrick ES, Rigby AS, Atkin SL. Insulin resistance, the metabolic syndrome, and complication risk in type 1 diabetes: "double diabetes" in the Diabetes Control and Complications Trial. Diabetes Care. 2007 Mar;30(3):707-12. doi: 10.2337/dc06-1982. PMID: 17327345 .

16. Kim MK, Han K, Koh ES, Kim ES, Lee MK, Nam GE, Kwon HS. Weight change and mortality and cardiovascular outcomes in patients with new-onset diabetes mellitus: a nationwide cohort study. Cardiovasc Diabetol. 2019 Mar 19;18(1):36. doi: 10.1186/s12933019-0838-9. PMID: 30890169; PMCID: PMC6423842.

17. Yamada E, Okada S, Nakajima Y, Bastie C, Tagaya Y, Osaki A, Shimoda $Y$, Shibusawa R, Saito T, Ozawa A, Yamada M. Assessment of factors determining an $\mathrm{HbAlc}$ concentration $\leq 7.5 \%$ in patients with type 1 diabetes. J Diabetes. 2018 Feb;10(2):140-147. doi: 10.1111/1753-0407.12572. Epub 2017 Jun 28. PMID: 28544548.

18. Alvim RO, Cheuhen MR, Machado SR, Sousa AG, Santos PC. General aspects of muscle glucose uptake. An Acad Bras Cienc. 2015 Mar;87(1):351-68. doi: 10.1590/0001-3765201520140225. Epub 2015 Mar 6. PMID: 25761221.

19. Corbin KD, Driscoll KA, Pratley RE, Smith SR, Maahs DM, Mayer-Davis EJ; Advancing Care for Type 1 Diabetes and Obesity Network (ACT1ON). Obesity in Type 1 Diabetes: Pathophysiology, Clinical Impact, and Mechanisms. Endocr Rev. 2018 Oct 1;39(5):629663. doi: 10.1210/er.2017-00191. PMID: 30060120.

20. Rawshani A, Rawshani A, Franzén S, Eliasson B, Svensson AM, Miftaraj M, McGuire DK, Sattar N, Rosengren A, Gudbjörnsdottir S. Mortality and Cardiovascular Disease in Type 1 and Type 2 Diabetes. N Engl J Med. 2017 Apr 13;376(15):1407-1418. doi: 10.1056/ NEJMoa1608664. PMID: 28402770. 